\title{
New Concepts in Geophysical Surveying and Data Interpretation for Permafrost Terrain
}

Christian Hauck*

Department of Geosciences, University of Fribourg, Fribourg, Switzerland

\begin{abstract}
This review focuses on advances in applications of geophysical methods to permafrost terrain that have emerged in 2007-12. Improvements in the four main geophysical techniques presently used in permafrost research (i.e. electric, electromagnetic, seismic and radar methods) and new or resurrected methods for permafrost applications are discussed. Advances in geophysical monitoring and quantitative interpretation of geophysical survey results are presented, especially for ground ice and water content. Electrical resistivity is now used operationally for long-term monitoring of ice content, as well as for short-term process studies. Quantitative approaches to determine realistic ice and liquid water content values and their spatial and temporal variability exist, but need to be further refined to be widely applicable for geotechnical and numerical modelling purposes. Copyright (C) 2013 John Wiley \& Sons, Ltd.
\end{abstract}

KEY WORDS: geophysical methods; monitoring; ice content; water content; mapping; review

\section{INTRODUCTION}

This article covers the major achievements in the application of geophysical methods to the study of permafrost between 2007 and April 2012. A benchmark review by Scott et al. (1990), discussing the relative advantages of various geophysical methods for permafrost research, remains a key reference, but has recently been supplemented by Kneisel et al. (2008) and Hauck and Kneisel (2008). Furthermore, a special issue of the Journal of Environmental and Engineering Geophysics, focusing on the application of geophysical methods to glacial and frozen materials, was presented by Kulessa and Woodward (2007). This paper will focus on developments since 2007 and especially on improvements regarding: (1) the monitoring of geophysical properties; (2) relations between geophysical and material properties (i.e. ice content, water content, temperature and porosity); and (3) new techniques that were not discussed in the review articles mentioned above.

Geophysical techniques enable the detection, monitoring and visualisation of subsurface permafrost characteristics indirectly and non-invasively from the surface. The information obtained may relate to shallow conditions (e.g. in the active layer), or to material properties several tens to hundreds of metres below the surface. The methods rely on

* Correspondence to: C. Hauck, Department of Geosciences, University of Fribourg, Chemin du Musée 4, 1700 Fribourg, Switzerland. E-mail: christian.hauck@unifr.ch the mathematical inversion of data measured at the surface to yield geophysical model parameters at greater depth, for instance, specific resistivity, seismic or electromagnetic wave velocity, or permittivity. Inversion is usually poorly constrained and, therefore, ambiguous. In practice, userdefined constraints, such as maximum or minimum values of the geophysical property, or spatial filtering, are added to form so-called regularisation parameters (e.g. Oldenburg and Li, 2005). Consequently, several inversion models of, for instance, a two-dimensional (2D) electrical resistivity distribution will fit a set of observed apparent resistivity data equally well.

This characteristic implies that, in principle, geophysical and periglacial knowledge have to be combined to conduct successful permafrost research with geophysical methods. In particular, problems concerning the reliability and overinterpretation of data are and should be as much a focus for theoretical geophysical studies as for applied permafrost research - to understand the required quality of geophysical data to enable confident interpretation. Unfortunately, relevant research is commonly published in a wide range of scientific journals (geophysical, cryospheric and geomorphological), each of which has a distinctive readership. The application of geophysical methods in permafrost terrain would certainly benefit from stronger collaboration between these communities. Here, new developments in both geophysical methods and their application in permafrost terrain will be presented. 


\section{METHODS, IMPROVEMENTS AND POTENTIALS}

Traditionally, electrical, electromagnetic and seismic methods have been the principal geophysical techniques used in permafrost research. Electrical resistivity tomography (ERT, also called electrical resistivity imaging), electromagnetic (EM) induction, ground-penetrating radar (GPR) and refraction seismics are the most common techniques. Other methods that were used in the 1970s (Scott et al., 1990), but have subsequently fallen from favour (e.g. self-potential (SP), gravimetry or reflection seismic), will probably be more frequently applied in the future due to improvements in data acquisition and processing techniques, as well as the availability of industrygenerated data-sets (reflection seismics).

In the following, new and innovative applications of the latter group will be briefly described, before focusing on new developments in the application and processing of the four main methods (ERT, EM, GPR, refraction seismics). Note, however, that all the methods described below have already been applied to a variety of geoscientific problems by the geophysical community, the details of which are not focus of this review. In the present review, the term 'new' denotes 'new in its application to permafrost-related problems'.

\section{New or 'Rediscovered' Electrical/Electromagnetic Techniques}

Despite considerable success in the application of ERT to permafrost-related problems (e.g. Fortier et al., 2008; Hilbich et al., 2008; Krautblatter et al., 2010; Isaksen et al., 2011; Lewkowicz et al., 2011; Scapozza et al., 2011; Overduin et al., 2012; Rödder and Kneisel, 2012), some aspects of the method restrict its application in particular environments, especially the need for good galvanic contact between the electrodes and the ground. As an alternative, capacitively coupled resistivity (CCR) methods have been extensively tested and successfully applied (De Pascale et al., 2008; Fortier and Savard, 2010). Such methods overcome the problem of direct (galvanic) electrode contact by coupling an alternating current across a transmitter-earth capacitor. However, CCR methods are more difficult to apply with respect to high data quality than ERT, especially with respect to the correct (and stable) alignment of sensors while towing the system and the small signal changes expected in sensor capacitances during monitoring (Wilkinson et al., 2011).

SP measurements are increasingly applied as a passive electrical method that complements ERT (Scapozza et al., 2008; Sedov et al., 2008), again partly as a result of improved data acquisition techniques. SP surveys measure or monitor the natural electrical potential. SP was frequently used in the past to detect water flows in permafrost areas (Scott et al., 1990), but because the measured potential differences are commonly small, considerable care is needed to deploy non-polarising sensors accurately. For example, Sedov et al. (2008) used SP to monitor water seepage through an industrial tailings dam, and Scapozza et al. (2008) applied it to characterise intra-rock glacier water flow in the Swiss Alps. Parameswaran and Burn (2008) monitored electrical freezing potentials during permafrost aggradation at Illisarvik, Canada, using a borehole electrode probe. These potentials arise due to charge separation during phase change in water and can be used to identify freezing processes more clearly than with temperature sensors alone.

Nuclear magnetic resonance (NMR) provides a comparatively new EM method for investigating permafrost (Lehmann-Horn et al., 2011). As with CCR and EM induction methods, this technique is not affected by sensor-toground coupling problems, because direct contact with the ground is unnecessary. However, it is strongly affected by EM noise, which is, luckily, not very common in permafrost terrain. NMR is directly sensitive to liquid water content, as it utilises a strong magnetic field to align the spins of $\mathrm{H}$ protons and monitors the decay of the polarised field when the magnetic field is turned off. The decay signal is then inverted to yield liquid (unbound) water within the subsurface. A significant amount of liquid water has to be present to be detectable, but it can be confined to thin layers of a few metres (Lehmann-Horn et al., 2011).

Finally, industrial-type surveys or industrial data-sets have been increasingly used to answer scientific questions. Seismic methods using a large number of geophones and shot points (up to one million direct arrival travel-times were manually picked to generate a P-wave velocity tomography, see Ramachandran et al., 2011) allow a high-resolution threedimensional (3D) representation of frozen ground characteristics. Similarly, the calibration of high-resolution spatial data (e.g. CCR and GPR) with borehole data or even borehole geophysics, as is common in industrial exploration surveys, can help improve the interpretation of geophysical data for sites where no borehole data are available (Milanovskyi et al., 2008).

\section{Improvements in Data Acquisition and Processing of Standard Techniques in Permafrost Terrain (ERT, EM, GPR, Refraction Seismics)}

Traditionally, geophysical surveys have been conducted along transects or profiles, yielding 2D vertical sections characterising geophysical properties in the subsurface. Alternatively, 2D anomaly maps (e.g. gravity or electrical conductivity anomalies) have been obtained by measuring the bulk (mean) value of a geophysical property over a given depth. Extensions of such surveys have become standard in many permafrost applications: (1) spatial extension to 3D; and (2) temporal extension by precise repetition of measurements, commonly with fixed sensor installations (monitoring).

\section{Improvements Regarding Spatial Representation.}

Several approaches are used to obtain 3D distributions of geophysical properties: (1) measurements covering the complete half-space of the subsurface with corresponding 
3D data processing/data inversion; (2) several parallel and/ or orthogonal survey lines with corresponding 3D migration/inversion; and (3) survey lines with 3D interpolation. Whereas the first approach is often time-consuming and costly, and the third approach may not provide additional insight compared to analysing the survey lines individually, the second approach is feasible for most geophysical techniques. Such applications have increased recently (e.g. GPR: Brosten et al., 2009; ERT: Rödder and Kneisel, 2012), allowing for detailed permafrost and active-layer mapping in 3D. In all cases, the measurement effort is higher than with single survey lines. Application is facilitated through fast data acquisition systems, such as GPR systems mounted on sledges/mats including specifically designed rough-terrain antennae, or multi-channel ERT systems which measure up to ten different fourelectrode combinations, 'quadrupoles', at the same time (Wilkinson et al., 2012). However, planting electrodes/ geophones on a 3D grid is still time-consuming, and installation time scales linearly with the number of sensors used (Rödder and Kneisel, 2012).

Airborne geophysical surveys, usually involving EM induction sensors, are also used to map geophysical properties over large areas. For instance, an airborne multi-frequency EM survey was used by Minsley et al. (2012) to map the regional-scale permafrost distribution in the Yukon Flats area, Alaska, inverting around 500000 individual EM soundings. This approach, though costly, enables the development of detailed regional-scale images of permafrost distribution and its vertical extent.

\section{Monitoring}

Monitoring pilot studies using geophysical methods in permafrost terrain were started during the late 1990s2000s, especially using ERT with permanent electrode arrays (Hauck, 2002; Kneisel et al., 2008). In several cases, changes in subsurface ice content in mountain permafrost terrain were detected over a time span of up to ten years (e.g. Hilbich et al., 2008; Isaksen et al., 2011). Other applications of ERT monitoring include permafrost rock walls (Krautblatter et al., 2010), glacier forefields (Kneisel et al., 2008), rock glaciers and talus slopes (Hilbich et al., 2009; Kneisel and Schwindt, 2008). Recently, an operational ERT monitoring network was installed within the Swiss permafrost monitoring network PERMOS, which now includes ten ERT monitoring stations in the Swiss Alps (http://www.permos.ch). Continuous, automated ERT monitoring systems for permafrost regions were recently introduced, utilising a solar panel-driven ERT system to monitor 2D resistivity changes on a daily basis (Figure 1; Hilbich et al., 2011). Pilot studies have also been initiated for resistivity monitoring using CCR (Wilkinson et al., 2011).

Multi-channel GPR has been used to monitor the unfrozen water content distribution in the active layer (e.g. Westermann et al., 2010). In contrast to standard GPR surveys, where one set of transmitter and receiver antennae is used, multi-channel GPR uses several receiving and/or several transmitting antennae. This way, multiple measurements from the same reflector point at a certain depth are obtained, but with different pathways for the EM pulse (Wollschläger et al., 2010). As in standard, but timeconsuming, (CMP) surveys, the ambiguity of not being able to resolve EM propagation velocity and depth of the reflector at the same time can be resolved.

Refraction seismic monitoring is a method with potentially high logistical requirements, but it promises to unambiguously detect ice loss caused by permafrost degradation. Hilbich (2010) tested the technique successfully in fine-grained and coarse-grained permafrost terrain. As a result of the large P-wave velocity contrast between ice $(3500 \mathrm{~m} / \mathrm{s})$, water $(1500 \mathrm{~m} / \mathrm{s})$ and air $(300 \mathrm{~m} / \mathrm{s})$, and owing to the propagation of seismic waves through the solid (ice or soil/rock matrix) phase, large changes in ice content can be more clearly detected by seismic monitoring than with ERT (Hilbich, 2010).

Reducing Ambiguity - Improvements in Data Processing.

There have been numerous improvements in the processing capability of geophysical data (e.g. processing time, accuracy, reliability, representativeness, joint interpretations/inversions), which are now reported in the geophysical literature (e.g. Day-Lewis et al., 2005; Maurer et al., 2010;

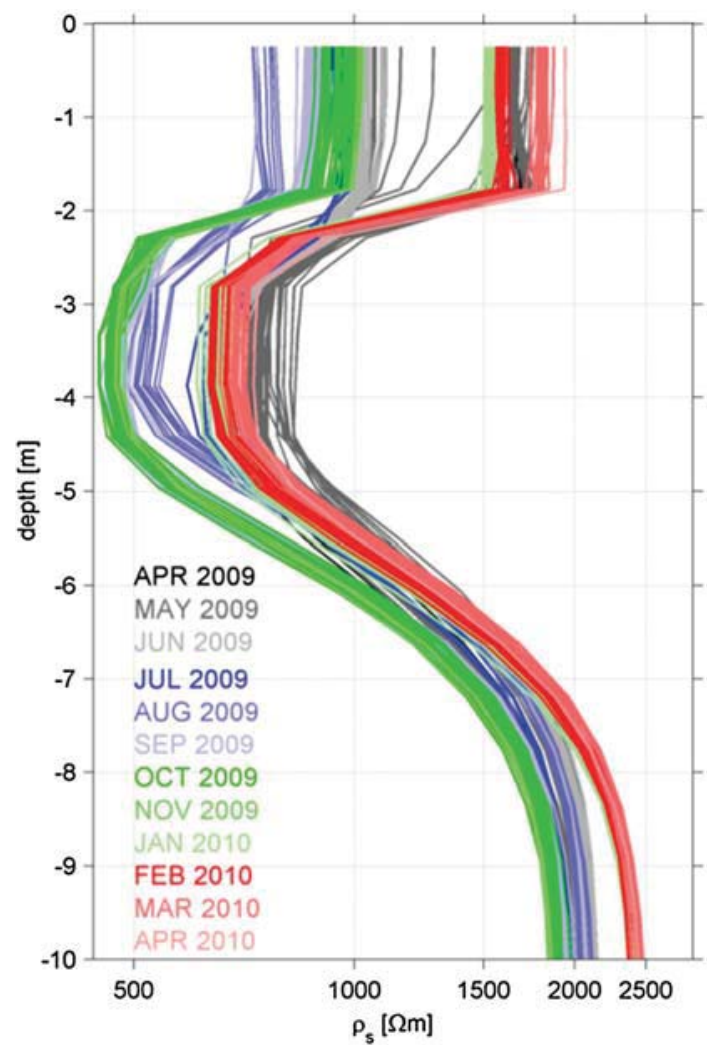

Figure 1 Monthly specific resistivity values from the inversion results of continuous electrical resistivity tomography measurements at Schilthorn, Swiss Alps. The values are shown along one-dimensional profiles at the B14 borehole location (virtual boreholes). Modified after Hilbich et al. (2011). 
Wilkinson et al., 2012). Here, I comment briefly on permafrost-related improvements.

Most of the uncertainty inherent to geophysical surveys stems from the under-determined inversion problem (i.e. the geometric constraint of trying to infer a multitude of subsurface model parameters from a limited number of surface measurements, usually with unknown measurement accuracy). Krautblatter et al. (2010) showed in an ERT case study from the German Alps that error models (i.e. spatial representations of measurement errors obtained for a specific measurement profile) may be used to constrain the inversion model and thereby reduce ambiguity. In addition, or as an alternative, in-situ subsurface data from boreholes may be used to constrain the inversion model (Fortier et al., 2008). Similarly, laboratory data (e.g. Draebing and Krautblatter, 2012; Overduin et al., 2012) can be used to relate known geologic or thermal conditions to geophysical properties and also to constrain the inversion.

The reliability of inversion models can be assessed by various methods ('appraisal methods'; Oldenburg and Li, 1999). These include, for example, forward-inverse cycles, which consist of repetitive forward calculations of virtual measurement data from a synthetic model (e.g. apparent resistivities calculated from a specific resistivity model) and subsequent inversion of these virtual measurements to find the model which best fits the real observations for a given measurement geometry (Fortier et al., 2008; Kneisel et al., 2008). Forward-inverse cycles have also been used to analyse the theoretical potential of detecting ice content changes in the subsurface for a given monitoring method, measurement configuration and inversion algorithm (Hilbich et al., 2009). In addition, the depth-of-investigation method (Oldenburg and $\mathrm{Li}, 1999$ ) and/or the analysis of resolution and sensitivity matrices are frequently used to assess the trustworthiness of the results, especially for larger depths (Fortier et al., 2008; Hilbich et al., 2009; Wilkinson et al., 2012). Nevertheless, there can always be large uncertainty in the interpretation of geophysical surveys due to ambiguities in relating geophysical properties uniquely to material composition, such as the wellknown problem of differentiating between ice and rock in electrical and seismic surveys (Hauck et al., 2011).

\section{POST-INVERSION PROCESSING}

In general, the application of geophysical methods to permafrost problems consists of three steps: (1) field measurements; (2) data processing, specifically data inversion; and (3) interpretation in the periglacial/geological/hydrological context. Recently, an additional processing step has often been included that is, in effect, post-inversion processing. It is important and necessary to determine the relation between the geophysical property that has been measured electrical resistivity, seismic velocity or permittivity - and the permafrost property of interest - ice content, water content or ground temperature (Kneisel et al., 2008). Such relations are usually applied to fully processed geophysical data, hence the term post-inversion processing.
There are well-used relations, or mixing rules (e.g. the complex refractive index model (CRIM) formula, relating permittivity to water content), and Archie's law relating electrical resistivity to porosity and saturation for determining water content; similarly, there are relations between seismic P-wave velocity and porosity/water content (Carcione et al., 2007). For a few geophysical methods, such as gravimetry, there are direct relations between the measured property (density) and the permafrost property (ice content) (Hausmann et al., 2007).

As a specific permafrost approach, Hauck et al. (2011) combined several existing relationships into a so-called four-phase model, yielding ice, water and air content within the subsurface from ERT and seismic inversion results for a given porosity model (Figure 2). The approach is especially useful if data collected in a monitoring programme are used to yield temporal changes in the phase contents, because, under such conditions, porosity may be considered constant. Hausmann et al. (2007) who combined seismic, GPR and gravimetry measurements to calculate ice content and porosity values for a rock glacier in the Austrian Alps were able to distinguish lateral ice content differences of ten to 15 per cent within the rock glacier body. Finally, using laboratory data on electrical resistivity changes during the freezing of ground materials, Krautblatter et al. (2010) estimated temperatures within permafrost from ERT measurements for a site in the German/Austrian Alps. All the above approaches aim at quantifying changes in ice content or temperature using only non-invasive geophysical data.

\section{APPLICATIONS}

The applications of geophysical techniques to permafrost problems are diverse, not only regarding the methods used, but also with respect to the purposes of investigation (geotechnical, climatological, geomorphological, hydrological), the terrain types examined (lowland, mountain and marine/ coastal environments) and the spatial scale of the study.

Innovative case studies using geophysical techniques were presented by: Overduin et al. (2012) to detect the degradation of near-shore subsea permafrost; Langston et al. (2011) regarding hydrological pathways in the presence of ice within moraines and rock glaciers in mountain catchments; Scapozza et al. (2011) and Kneisel and Schwindt (2008) to detect internal air circulation in periglacial talus slopes; Schwamborn et al. (2008) to define patchy permafrost occurrences in volcanic material in maritime Antarctica; Lewkowicz et al. (2011), Isaksen et al. (2011) and Rödder and Kneisel (2012) regarding local, heterogeneous occurrence of permafrost and its corresponding subsurface temperature in Yukon, Norway, and Switzerland; and Sedov et al. (2008) for monitoring industrial impacts on permafrost in Siberia.

Quantitative comparisons of geophysical field data with thermal subsurface models are especially useful to constrain both parameterisations of thermal models and under-determined parts of geophysical inversion models (Scherler et al., 2010; Fortier et al., 2011). 


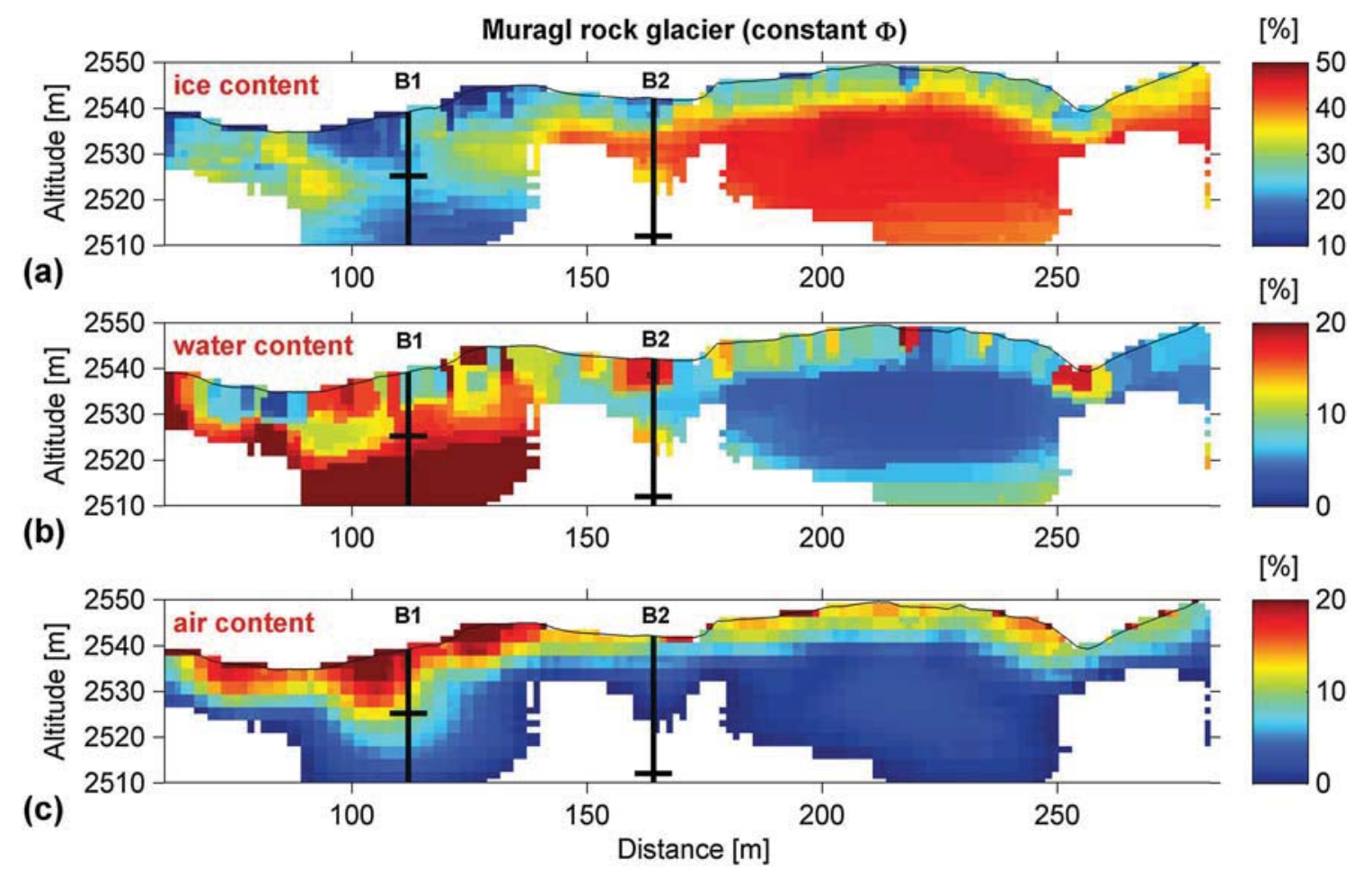

Figure 2 (a) Ice, (b) water and (c) air content simulation results of the four-phase model for Muragl rock glacier, Swiss Alps, calculated from electrical resistivity tomography and refraction seismic measurements and a constant porosity model of 50 per cent. The locations of two boreholes are indicated by black vertical lines. The depth of the water table is indicated by black horizontal lines (taken from Hauck et al., 2011).

\section{CONCLUDING REMARKS AND OUTLOOK}

Recently, a number of studies have applied geophysical methods to permafrost-related problems. The majority of these studies apply ERT, seismic or GPR techniques. Consequently, these three techniques have seen several important technical developments, especially regarding their 3D spatial representation, monitoring capabilities and potential for quantitative permafrost interpretation.

Apart from these well-established methods, several new or rediscovered geophysical techniques may be applied more often in the future, especially if data-processing techniques can be improved and surveying costs can be reduced. These techniques may include NMR, SP monitoring, complex resistivity methods, airborne EM methods and gravimetry.

With respect to application, increasingly detailed information is being drawn from geophysical surveys, including quantitative estimation of water storage, ice contents, water flow and temperature. In the future, we can expect not only joint interpretation, but also joint processing of geophysical monitoring data and thermal/hydrological models (e.g. assimilating geophysical monitoring data in models of permafrost evolution or by constraining geophysical inversion with permafrost thermal/hydrological model outputs).

While the increased use of geophysics in permafrost studies is welcome, further collaboration between the permafrost and geophysical communities is needed to ensure that appropriate methods are chosen, realistic objectives are set and data-processing standards are met. Overprocessing with unrealistic accuracy levels during inversion should be avoided and, most importantly, data should not be over-interpreted beyond the level of the accuracy and reliability of the methods used to obtain the data.

\section{ACKNOWLEDGEMENTS}

I would like to thank the German and Swiss National Science Foundations (Sensitivity of mountain permafrost to climate change (SPCC) project: DFG HA3475/3-1; The temporal evolution of mountain permafrost in Switzerland (TEMPS) project: SNF CRSII2_136279) for financial support. I also thank the reviewers for their constructive and helpful reviews, and C. Burn and J. Murton for generous and extensive editing.

\section{REFERENCES}

Brosten TR, Bradford JH, McNamara JP, Gooseff MN, Zarnetske JP, Bowden WB,
Johnston ME. 2009. Estimating 3D variation in active-layer thickness beneath arctic streams using ground-penetrating radar. Journal of Hydrology 373: 479-486.
Carcione JM, Ursin B, Nordskag JI. 2007. Cross-property relations between electrical conductivity and the seismic velocity of rocks. Geophysics 72: E193-E204. 
Day-Lewis FD, Singha K, Binley A. 2005. Applying petrophysical models to radar traveltime and electrical resistivity tomograms: resolution-dependent limitations. Journal of Geophysical Research 110: B082006. DOI: 10.1029/2004JB003569

De Pascale GP, Pollard WH, Williams KK. 2008. Geophysical mapping of ground ice using a combination of capacitive coupled resistivity and ground-penetrating radar, Northwest Territories, Canada. Journal of Geophysical Research 113: F02S90. DOI: 10.1029/2006JF000585

Draebing D, Krautblatter M. 2012. P-wave velocity changes in freezing hard low-porosity rocks: a laboratory-based time-average model. The Cryosphere 6: 1163-1174. DOI: $10.5194 /$ tc-6-1163-2012

Fortier R, Savard C. 2010. Engineering geophysical investigation of permafrost conditions underneath airfield embankments in northern Quebec (Canada). Sixième Conférence canadienne sur le pergélisol, GEO2010, Calgary, Alberta, Canada: 1307-1314.

Fortier R, LeBlanc A-M, Allard M, Buteau S, Calmels F. 2008. Internal structure and conditions of permafrost mounds at Umiujaq in Nunavik, Canada, inferred from field investigation and electrical resistivity tomography. Canadian Journal of Earth Sciences 45: $367-387$.

Fortier R, LeBlanc A-M, Yu W. 2011. Impacts of permafrost degradation on a road embankment at Umiujaq in Nunavik (Quebec). Canada. Canadian Geotechnical Journal 48: 720-740. DOI: 10.1139/T10-101.

Hauck C. 2002. Frozen ground monitoring using DC resistivity tomography. Geophysical Research Letters 29: 2016. DOI: 10. 1029/2002GL014995.

Hauck C, Kneisel C. 2008. Applied Geophysics in Periglacial Environments. Cambridge University Press: Cambridge; 240pp.

Hauck C, Böttcher M, Maurer H. 2011. A new model for estimating subsurface ice content based on combined electrical and seismic data sets. The Cryosphere 5: 453-468.

Hausmann H, Krainer K, Brückl E, Mostler W. 2007. Internal structure and ice content of Reichenkar rock glacier (Stubai Alps, Austria) assessed by geophysical investigations. Permafrost and Periglacial Processes 18: 351-367. DOI: 10.1002/ppp.601.

Hilbich C. 2010. Time-lapse refraction seismic tomography for the detection of ground ice degradation. The Cryosphere 4: 243-259. DOI: $10.5194 / t c-4-243-2010$.

Hilbich C, Hauck C, Hoelzle M, Scherler M, Schudel L, Völksch I, Vonder Mühll D, Mäusbacher R. 2008. Monitoring mountain permafrost evolution using electrical resistivity tomography: A 7-year study of seasonal, annual, and long-term variations at
Schilthorn, Swiss Alps. Journal of Geophysical Research 113: F01S90. DOI: 10. 1029/2007JF000799.

Hilbich C, Marescot L, Hauck C, Loke M, Mäusbacher R. 2009. Applicability of electrical resistivity tomography monitoring to coarse blocky and ice-rich permafrost landforms. Permafrost and Periglacial Processes 20: 269-284. DOI: 10.1002/ppp.652

Hilbich C, Fuss C, Hauck C. 2011. Automated time-lapse ERT for improved process analysis and monitoring of frozen ground. Permafrost and Periglacial Processes 22: 306-319. DOI: 10.1002/ppp.732

Isaksen $\mathrm{K}$, Ødegård RS, Etzelmüller $\mathrm{B}$, Hilbich C, Hauck C, Farbrot H, Eiken T, Hygen HO, Hipp T. 2011. Degrading Mountain Permafrost in Southern Norway: Spatial and Temporal Variability of Mean Ground Temperatures, 1999-2009. Permafrost and Periglacial Processes 22: 361-377. DOI: 10.1002/ppp.728

Kneisel C, Schwindt D. 2008. Geophysical mapping of isolated permafrost lenses at a sporadic permafrost site at low altitude in the Swiss Alps. In Proceedings of the 9th International Conference on Permafrost, Fairbanks, Alaska, Kane DL, Hinkel KM (eds). Institute of Northern Engineering, University of Alaska Fairbanks: Fairbanks, Alaska, USA; 959-964.

Kneisel C, Hauck C, Fortier R, Moorman B. 2008. Advances in geophysical methods for permafrost investigations. Permafrost and Periglacial Processes 19: 157-178. DOI: $10.1002 /$ ppp.616

Krautblatter M, Verleysdonk S, FloresOrozco A, Kemna A. 2010. Temperaturecalibrated imaging of seasonal changes in permafrost rock walls by quantitative electrical resistivity tomography (Zugspitze, German/Austrian Alps). Journal of Geophysical Research Earth Surface 115: F02003.

Kulessa B, Woodward J. 2007. Introduction to this special issue of JEEG; the geophysics of glacial and frozen materials. Journal of Environmental and Engineering Geophysics 12: $1-2$.

Langston G, Bentley LR, Hayashi M, McClymont AF, Pidlisecky A. 2011. Internal structure and hydrological functions of an alpine proglacial moraine. Hydrological Processes 25: 29672982. DOI: $10.1002 / \mathrm{hyp} .8144$.

Lehmann-Horn JA, Walbrecker JO, Hertrich M, Langston G, McClymont AF, Green AG. 2011. Imaging groundwater beneath a rugged proglacial moraine. Geophysics 76: B165-B172.

Lewkowicz AG, Etzelmüller B, Smith SL. 2011. Characteristics of discontinuous permafrost based on ground temperature measurements and electrical resistivity tomography, southern Yukon, Canada.
Permafrost and Periglacial Processes 22 320-342. DOI: 10.1002/ppp.703

Maurer H, Curtis A, Boerner DE. 2010. Recent advances in optimized geophysical survey design. Geophysics 75: 75A177-75A194.

Milanovskyi S, Velikin S, Istratov V. 2008. Geophysical study of talik zones, western Yakutia. In Proceedings of the Ninth International Conference on Permafrost, Fairbanks, Alaska, Kane DL, Hinkel KM (eds). Institute of Northern Engineering, University of Alaska Fairbanks: Fairbanks, Alaska, USA; 1221-1226.

Minsley BJ, Abraham JD, Smith BD, Cannia JC, Voss CI, Jorgenson MT, Walvoord MA, Wylie BK, Anderson L, Ball LB, Deszcz-Pan M, Wellman TP, Ager TA. 2012. Airborne electromagnetic imaging of discontinuous permafrost. Geophysical Research Letters 39: L02503. DOI: 10.1029/2011GL050079.

Oldenburg DW, Li YG. 1999. Estimating depth of investigation in DC resistivity and IP surveys. Geophysics 64: 403-416. DOI: 10.1190/1.1444545

Oldenburg DW, Li Y. 2005. Inversion for applied geophysics: A tutorial. In Nearsurface Geophysics, Butler DK (ed). Society of Exploration Geophysicists: 89-150. DOI: 10.1190/1.9781560801719.ch5

Overduin PP, Westermann S., Yoshikawa K, Haberlau T., Romanovsky V., Wetterich S. 2012. Geoelectric observations of the degradation of nearshore submarine permafrost at Barrow (Alaskan Beaufort Sea). Journal of Geophysical Research 117: F02004. DOI: 10.1029/2011JF002088.

Parameswaran VR, Burn CR. 2008. Electrical freezing potentials during permafrost aggradation at the Illisarvik Drained-Lake Experiment, western Arctic coast, Canada. In Proceedings of the Ninth International Conference on Permafrost, Fairbanks, Alaska, Kane DL, Hinkel KM (eds). Institute of Northern Engineering, University of Alaska Fairbanks: Fairbanks, Alaska, USA; $1363-1368$.

Ramachandran K, Bellefleur G, Brent T, Riedel M, Dallimore S. 2011. Imaging permafrost velocity structure using high resolution 3D seismic tomography. Geophysics 76: B187. DOI: 10.1190/geo2010-0353.1

Rödder T, Kneisel C. 2012. Permafrost mapping using quasi-3D resistivity imaging, Murtèl, Swiss Alps. Near Surface Geophysics 10: 117-127. DOI: 10.3997/ 1873-0604.2011029

Scapozza C, Gex P, Lambiel C, Reynard E. 2008. Contribution of self-potential (SP) measurements in the study of alpine periglacial hydrology: examples from the southern Swiss Alps. In Proceedings of the 9th International Conference on Permafrost, Fairbanks, Alaska, Kane DL, Hinkel KM 
(eds). Institute of Northern Engineering, University of Alaska Fairbanks: Fairbanks, Alaska, USA; 1583-1588.

Scapozza C, Lambiel C, Baron L, Marescot L, Reynard E. 2011. Internal structure and permafrost distribution in two alpine periglacial talus slopes, Valais, Swiss Alps. Geomorphology 132: 208-221.

Scherler M, Hauck C, Hoelzle M, Staehli M, Voelksch I. 2010. Meltwater infiltration into the frozen active layer at an Alpine permafrost site. Permafrost and Periglacial Processes 21: 325-334. DOI: 10.1002/ppp.694

Schwamborn G, Wagner D, Hubberten H. 2008. The use of GPR to detect active layer in young periglacial terrain of Livingston Island, Maritime Antarctica. Near Surface Geophysics 6: 327-332.
Scott W, Sellmann P, Hunter J. 1990. Geophysics in the study of permafrost. In Geotechnical and Environmental Geophysics, Ward S (ed). Society of Exploration Geophysics: Tulsa; 355-384.

Sedov B, Muslimov A, Tikhmenev P. 2008. Investigation and monitoring of tailing dams in northeast Russia using geoelectrical methods. In Proceedings of the Ninth International Conference on Permafrost, Fairbanks, Alaska, Kane DL, Hinkel KM (eds). Institute of Northern Engineering, University of Alaska Fairbanks: Fairbanks, Alaska, USA; 16071612.

Westermann S, Wollschläger U, Boike J. 2010. Monitoring of active layer dynamics at a permafrost site on Svalbard using multi-channel ground-penetrating radar. The Cryosphere 4: 475-487.

Wilkinson P, Chambers J, Kuras O, Meldrum P, Gunn D. 2011. Long-term time-lapse geoelectrical monitoring. First Break 29: 77-84.

Wilkinson P, Loke MH, Meldrum P, Chambers J, Kuras O, Gunn D, Ogilvy R. 2012. Practical aspects of applied optimized survey design for electrical resistivity tomography. Geophysical Journal International 189: $428-440$.

Wollschläger U, Gerhards H, Yu Q, Roth K. 2010. Multi-channel ground-penetrating radar to explore spatial variations in thaw depth and moisture content in the active layer of a permafrost site. The Cryosphere 4: 269-283. DOI: 10.5194/tc-4-269-2010. 